\title{
Mapeamento do termo adoecimento docente constantes no catálogo da CAPES
}

\author{
Mapping the term illness faculty contained in the CAPES catalog \\ Mapeo del término facultad de enfermedad contenido en el catálogo CAPES
}

Recebido: 26/07/2021 | Revisado: 07/08/2021 | Aceito: 09/08/2021 | Publicado: 14/08/2021

\author{
Débora Lisboa Correa Costa \\ ORCID: https://orcid.org/0000-0002-9541-5465 \\ Universidade Federal do Estado do Pará, Brasil \\ E-mail: debylisboa2007@yahoo.com.br \\ Anderson da Silva Costa \\ ORCID: https://orcid.org/0000-0002-3955-1817 \\ Biodiversidade e Biotecnologia da Amazônia Legal, Brasil \\ E-mail: anderson.costa@embrapa.br
}

\begin{abstract}
Resumo
Em virtude da necessidade de se analisar a ocorrência do número de docentes que adoecem por diversos motivos nas escolas no Brasil este estudo tem como objetivo catalogar as produções acadêmicas Stricto Sensu que constam na Coordenação de Aperfeiçoamento de Pessoal de Nível Superior (Capes) e que abordam o tema adoecimento Docente. O propósito do levantamento foi elaborar um panorama quantitativo da produção científica e analisar a quantidade de publicações que investigaram essa temática nos últimos treze anos. A pesquisa caracteriza-se como um estudo bibliográfico com abordagem quantitativa. $\mathrm{O}$ levantamento foi realizado utilizando-se o descritor adoecimento escolar entre aspas, com os filtros dissertações e teses no período de 2007 a 2020 . O estudo registrou um total de trinta e cinco produções científicas com essa temática, sendo cinco pesquisas classificadas na modalidade de Mestrado Profissional, vinte e duas dissertações de Mestrado acadêmico e oito teses de Doutorado. Os dados revelaram que o ano de 2015 foi período que registrou maior concentração dessa temática com oito incidências de pesquisas no ramo, seguido do ano de 2017, que apontou seis ocorrências. Em média essa temática registrou 2,5 por ano de incidência ao longo da série temporal, demonstrando uma pequena produção Strito Sensu sobre o tema no Brasil. Entretanto, vale ressaltar que uma dissertação ou tese de mestrado pode gerar no mínimo 2 a 3 artigos acadêmicos.
\end{abstract}

Palavras-chave: Mapeamento; Capes; Docente; Saúde.

\begin{abstract}
Due to the need to analyze the occurrence of the number of teachers who get sick for various reasons in schools in Brazil, this study aims to catalog the Stricto Sensu academic productions listed in the Coordination for the Improvement of Higher Education Personnel (Capes) and that address the Faculty illness theme. The purpose of the survey was to elaborate a quantitative overview of scientific production and analyze the number of publications that investigated this theme in the last thirteen years. The research is characterized as a bibliographic study with a quantitative approach. The survey was carried out using the descriptor school illness in quotation marks, with the filters dissertations and theses in the period from 2007 to 2020 . The study recorded a total of thirty-five scientific productions with this theme, with five studies classified in the Master's mode Professional, twenty-two academic Master's dissertations and eight Doctoral theses. The data revealed that the year 2015 was the period with the highest concentration of this theme with eight incidences of research in the field, followed by the year 2017, which showed six occurrences. On average, this theme registered 2.5 incidence per year throughout the time series, demonstrating a small Srito Sensu production on the theme in Brazil. However, it is noteworthy that a dissertation or master's thesis can generate at least 2 to 3 academic articles. Keywords: Mapping; Capes; Teacher; Health.
\end{abstract}

\section{Resumen}

Debido a la necesidad de analizar la ocurrencia del número de docentes que se enferman por diversas causas en las escuelas de Brasil, este estudio tiene como objetivo catalogar las producciones académicas Stricto Sensu enumeradas en la Coordinación de Perfeccionamiento del Personal de Educación Superior (Capes) y que abordar el tema de la enfermedad de la facultad. El propósito de la encuesta fue elaborar un panorama cuantitativo de la producción científica y analizar el número de publicaciones que investigaron este tema en los últimos trece años. La investigación se caracteriza por ser un estudio bibliográfico con enfoque cuantitativo. La encuesta se realizó utilizando el descriptor enfermedad escolar entre comillas, con los filtros disertaciones y tesis en el período 2007-2020. El estudio registró un total de treinta y cinco producciones científicas con esta temática, con cinco estudios clasificados en el Máster. modalidad Profesional, veintidós disertaciones académicas de maestría y ocho tesis doctorales. Los datos revelaron que el año 2015 fue el período con mayor concentración de este tema con ocho incidencias de investigación en el campo, 
seguido por el año 2017, que mostró seis ocurrencias. En promedio, este tema registró una incidencia de 2,5 por año a lo largo de la serie temporal, lo que demuestra una pequeña producción de Srito Sensu sobre el tema en Brasil. Sin embargo, es de destacar que una disertación o tesis de maestría puede generar al menos 2 a 3 artículos académicos.

Palabras clave: Cartografia; Capes; Profesor; Salud.

\section{Introdução}

As pesquisas denominadas 'estado da arte' são definidas como de caráter bibliográfico e possuem o propósito de mapear e debater determinada produção acadêmica. Segundo Ferreira (2002), este tipo de metodologia de pesquisa possibilita divulgar à sociedade um conhecimento já construído e produzido, que cresce de maneira acelerada. Admite-se a revisão bibliográfica como de grande importância para o desenvolvimento da pesquisa científica uma vez que permite a identificação, organização e sistematização do conhecimento já produzido sobre determinado tema, além de permitir uma reflexão e síntese desta produção para, posteriormente, investigar o que ainda não foi feito (Piton \& Machado 2019).

O surgimento da internet e a facilidade de acesso por meio de páginas eletrônicas permite a leitor o contato com um número demasiado de pesquisas sobre diversos temas, entretanto, diante de uma infinidade de informações que segue um fluxo contínuo existe a necessidade de seleção de assuntos específicos quando um autor deseja aprofundar seus conhecimentos e/ou escrever sobre um determinado assunto. A criação de portais de teses e dissertações, nos quais os trabalhos são publicados integralmente, tem possibilitado a acessibilidade a qualquer usuário da internet, potencializa a divulgação e o acesso a esses documentos (Lopes \& Romancini, 2006).

Neste contexto é possível perceber a importância de pesquisas do estado da arte uma vez que permitem revelar o conjunto de produções publicadas sobre uma temática particular, como explica Ferreira e Matos (2011, p. 3):

[...]diante da necessidade de identificar o avanço e as lacunas nas pesquisas científicas a pesquisa conhecida como "Estado da Arte ou Estado do Conhecimento" apresentam em comum o desafio de mapear determinada produção acadêmica em diferentes campos do conhecimento. Na pesquisa Estado da Arte é realizado um mapeamento da produção do conhecimento de determinada área específica. O mapeamento permite que o pesquisador perceba os avanços e as lacunas do objeto de estudo em questão.

Diante da consciência dos benefícios que este tipo de pesquisa oferece, foi realizado o levantamento do tema “Adoecimento Docente”, no Portal de Periódicos da CAPES. O referido Portal foi escolhido como fonte de produções científicas por ser uma biblioteca virtual que reúne e disponibiliza dissertações e teses que atendem as demandas de diversos setores. Vale ressaltar a definição que os autores Piton e Machado (2019), apontam para o Portal de Periódicos da Capes, como sendo uma ferramenta de avaliação e regulação dos cursos de Pós-graduação de grande importância para a promoção da pesquisa científica no Brasil.

Diante da infinidade de temas, à docência destaca-se por ser, historicamente, uma profissão sobre a qual têm-se depositado muitas demandas ao longo de sua prática, pois é uma das profissões que exige um planejamento prévio de suas atividades e a conquista diária da atenção de seu público, além da capacitação profissional que deve ocorrer de forma paralela ao processo de ensino. Apesar de suas inúmeras atividades, os professores têm sido desvalorizados socialmente ao longo do tempo e isto tem ocasionado uma série de implicações para este profissional. Sobre o assunto, Benevides-Pereira (2012) alerta que os profissionais do ensino têm sido muito exigidos, porém pouco apoiado no Brasil. O autor complementa ainda que os professores tornaram-se um profissional carente de um olhar atento para as suas necessidades, afetando sua própria saúde.

Sobre este aspecto, Esteves (1999) afirma que com as transformações ocorridas, o professor acompanha perplexo esse atual contexto, que oferece baixo salário fazendo com que esse profissional tenha que ensinar em muitas escolas ao mesmo tempo gerando funções simultâneas e sobrecarga de trabalho. Assim, o docente vivencia um ambiente de estresse, falta de 
valorização profissional e financeira que ocasionam inúmeras doenças e síndromes (pânico, burnout, etc) que agridem os professores no cotidiano do trabalho.

Ao acompanhar as jornadas de trabalho dos profissionais do ensino, percebe-se que em sua maioria os docentes trabalham em três esferas escolares (normalmente municipal, estadual e/ou particular), em média três turnos, de períodos quer costumam ser longos, com refeições breves e deslocamentos corridos entre uma instituição e outra. Essa rotina costuma ser intensa, uma vez que inicia muito cedo pela manhã, sendo estendida, muitas vezes, até à noite em função da dupla ou tripla jornada de trabalho que ocasionam problemas de saúde gerados em detrimento das poucas horas de sono, má alimentação e ausência de tempo para o lazer. Sobre o assunto, estudos mostram que a prática docente desses profissionais requer um nível alto de concentração. "Quando o trabalho é desprovido de significação, não é reconhecido ou é uma fonte de ameaças à integridade física e/ou psíquica acaba por determinar sofrimento ao professor". (Tavares, 2007, p. 19).

Acredita-se que além, dos fatores apresentados anteriormente, Cardoso, Nunes e Moura (2019) complementam que o aumento da violência no cotidiano escolar (principalmente de alunos contra professores) e a insatisfação dos profissionais com as demandas cotidianas da profissão contribuem para o adoecimento docente. Lemos (2011) contribui sobre o tema, ao apontar como agentes de adoecimento docente as múltiplas atividades do professor, a polivalência, a intensificação e a sobrecarga de trabalho, o que, por sua vez, gera a necessidade de trabalhar no tempo de lazer, com consequências em termos de desgaste físico e psíquico, assim como dificuldades na relação familiar.

[...] "É o trabalho invadindo o espaço pessoal e privado, impedindo que o professor vivencie outras dimensões da vida, descanse, pense e refaça as energias para enfrentar o cotidiano no início da semana" (p.109).

Para Tundis e Monteiro (2018), ressalte-se que o comprometimento da saúde mental do professor é um problema que afeta a área educacional, pois independentemente do nível de ensino e instituição (pública ou privada) vai impactar diretamente na falta de motivação para o trabalho, nas relações estabelecidas no trabalho (entre professores, professor-aluno e professorgestor da instituição), na qualidade do ensino prestado ou ocasionará o afastamento do mesmo por longos períodos, exigindo que outros professores absorvam a carga horária de seus colegas de trabalhos que encontram-se com doenças como depressão ou síndrome de Burnout.

O estudo de Lima e Lima-Filho (2009) apontou que além da jornada exaustiva, os professores convivem com a falta de equipamentos para o desenvolvimento do trabalho. Tal fato apresenta-se como um dos maiores problemas enfrentados nas instituições públicas, inclusive necessitando que os docentes, muitas vezes, tenham que recorrer a recursos próprios para poder adquirir materiais necessários para a realização do seu trabalho, o que também se constitui como um fator de estresse e desestímulo para o profissional do ensino.

Assim, verificam-se neste contexto pesquisas que passam a denunciar a situação de precariedade das condições de trabalho dos docentes em todos os níveis de ensino, o que leva tais trabalhadores a passarem a ter desgastes físicos e emocionais (Assunção, 2003; Sampaio \& Marim, 2004). Outros estudos (Lago, Cunha \& Borges, 2015; Lima \& Lima-Filho, 2009) apontam ainda que o adoecimento docente não se restringe somente a educação básica, constatando-se também prejuízos semelhantes na saúde dos docentes universitários, originados por dificuldades nas condições de trabalho e pela sobrecarga de atividades.

Independentemente do nível de ensino que o docente atua, percebe-se que em ambas é possível notar a precariedade nas condições de trabalho, dificuldades de relacionamento socioprofissionais e o esgotamento emocional dos docentes investigados, podem ser entendidos como possíveis riscos à saúde mental na medida em que se considera que o nível crítico potencializa o sofrimento no trabalho, necessitando de ações imediatas a curto e médio prazo (Mendes \& Ferreira, 2007). 
[...] as condições de trabalho que essa categoria profissional está submetida têm sofrido severas transformações. Por exemplo, processo de desqualificação, desprofissionalização, intensificação do trabalho, flexibilização dos contratos, entre outros. Desse modo, todo o movimento referido tem contribuído para o definhamento da saúde dos trabalhadores da área, principalmente no que pese à saúde mental (Abonízio, 2012, p. 23).

Mancebo (2006) ressaltam que existem aqueles professores que ministram mais de um componente curricular e que exercem cargos e funções administrativos paralelamente à sala de aula, sobrecarregando seu trabalho. Novas demandas são somadas ao trabalho que os professores já desenvolviam. Existe ainda a realização de diversos procedimentos burocráticos, a desregulamentação da legislação trabalhista, o aumento dos contratos temporários, a falta de segurança, a violência, transferências involuntárias, falta de perspectiva com relação à carreira e preparo inadequado que fazem parte do quadro de precarização do trabalho docente.

Este cenário apresenta-se cada vez mais crítico ao considerar as mudanças nas práticas de ensino a partir da pandemia do coronavírus. O estudo de Andrade (2020) investigou a relação entre o adoecimento docente e as aulas remotas consequentes do estabelecimento das medidas protetivas ao COVID-19 em uma escola da rede pública do Distrito Federal. Os dados desta pesquisa apontaram que neste período os professores vivenciaram momentos intensos e diferenciados, tendo em vista que tiveram que lidar além do cansaço e sobrecarga usual, com o medo de contraírem o vírus e até mesmo irem a óbito, bem como, enfrentar o desafio de ministrarem aulas em plataformas digitais que não possuíam experiência de uso e suporte digital adequado para seu bom funcionamento.

Estudos atuais (Gonzalez, 2020; Oliveira \& Santos, 202; Pachiega \& Milani 2020) convergem em seus resultados ao apontarem que as enfermidades docentes anteriores a pandemia tornaram-se mais intensas ao somarem-se ao estresse, a ansiedade, a insegurança do desligamento imediato (no caso de profissionais temporários) e ao temor de resultados negativos referente a aprendizagem dos alunos que vivenciaram um formato híbrido de aula. Diante deste contexto, Marques (2021) alerta para a necessidade de descontruir a ideia errônea, dos responsáveis pelos alunos e dos demais membros da sociedade, que o professor em ensino remoto está despreocupado ou com uma carga horária menor de trabalho.

A pesquisa de Silva, Estrela, Lima e Abreu (2020) mostra que o adoecimento docente ocasionado pela pandemia do COVID-19 não se restringe a professores da educação básica, mas atinge também a professores universitários que enfrentam as pressões oriundas das instituições de ensino superior. Ao entrevistar docentes de universidades públicas, do quadro permanente de programas de pós-graduação Stricto Sensu no Rio Grande do Norte, Vasconcelos e Lima (2021) constataram que a relação entre vida laboral de professores universitários e seu adoecimento nem sempre tem sido registrada tendo em vista que as doenças de cunho emocional nem sempre são identificadas pelos profissionais do ensino.

Considerando que este novo contexto de pandemia e o desenvolvimento do ensino remoto evidenciaram ainda mais a necessidade retomar a discussão sobre o tema, acredita-se que é de suma importância realizar um levantamento das pesquisas produzidas a esse respeito, o que possibilita a efetivação do balanço das produções acadêmicas da área, uma vez que pesquisas desse tipo podem indicar a compreensão do estado atingido a esse respeito, analisando sua amplitude, tendências teóricas e vertentes metodológicas (Romanowski \& Ens, 2006, p. 40). Nesse sentido, o levantamento bibliográfico justifica-se por ser um importante instrumento das investigações acadêmicas e "revela explicitamente o universo de contribuições científicas de autores sobre um tema específico" (Santos \& Candeloro, 2006, p. 43). Para contribuir com as investigações acadêmicas, esse estudo tem como objetivo mapear o termo adoecimento docente constante no catálogo da Capes no período de 2007 a 2020.

\section{Metodologia}

O levantamento de dados desta pesquisa foi realizado no Portal de Teses e Dissertações da CAPES, utilizando o descritor “Adoecimento Docente” e foi aplicado o filtro temporal para o período 2007 a 2020. 
Ressalta-se que é de interesse deste estudo analisar as dissertações de mestrado e as teses de doutorado produzidas nos programas de pós-graduação Stricto Sensu das universidades brasileiras por possibilitarem a caracterização de temas específicos e da produção científica das diferentes áreas do conhecimento.

Esta pesquisa caracteriza-se como um estudo bibliográfico considerando a definição de Severino (2017) que afirma que: "A pesquisa bibliográfica é aquela que se realiza a partir do registro disponível, decorrente de pesquisas anteriores, em documentos impressos, como livros, artigos, teses, etc (Severino, 2017, p. 93). Para a análise dos dados, este mapeamento utilizou a abordagem quantitativa, considerando como referência Severino (2017).

Para alcançar seu objetivo, foi realizado o levantamento do número de produções científicas provenientes de mestrados acadêmico, mestrado Profissional e Doutorado que consta na plataforma da CAPES. Após o levantamento, foi delimitado a base temporal, onde o material analisado foi restringido a trabalhos publicados nos últimos 13 anos no Brasil. Assim, este estudo é integrado também pela abordagem qualitativa, portanto integrada de pesquisa. Para a análise do conteúdo das produções adotamos Bardin (2016), que se efetiva com base na análise da presença ou ausência de uma dada característica do conteúdo. Este estudo foi realizado durante o período de junho a julho de 2021.

\section{Resultados e Discussões}

O levantamento deste estudo permitiu concluir que há um total de 35 pesquisas com essa temática, sendo 5 (cinco) inseridas no Mestrado Profissional, 22 (vinte e duas) inseridas no Mestrado acadêmico e 8 (oito) no Doutorado, na série temporal delimitado, conforme é possível acompanhar a seguir (Figura 1).

A média das publicações Stricto Sensu no período estudado apontou um valor de 2,5 ocorrências por ano e um pico com a temática em 2015 com 8 publicações.

Vale ressaltar que em 1976, teve início o sistema de acompanhamento e avaliação da pós-graduação, coordenado pela Coordenação de Aperfeiçoamento de Pessoal de Nível Superior (CAPES), cuja ação consolidou o delineamento da pósgraduação no Brasil, com vistas à formação de quadros significativos de docentes para o Ensino Superior.

Figura 1. Distribuição das ocorrências do tema adoecimento docente nos últimos 13 nos de acordo com a base de dados da Capes.

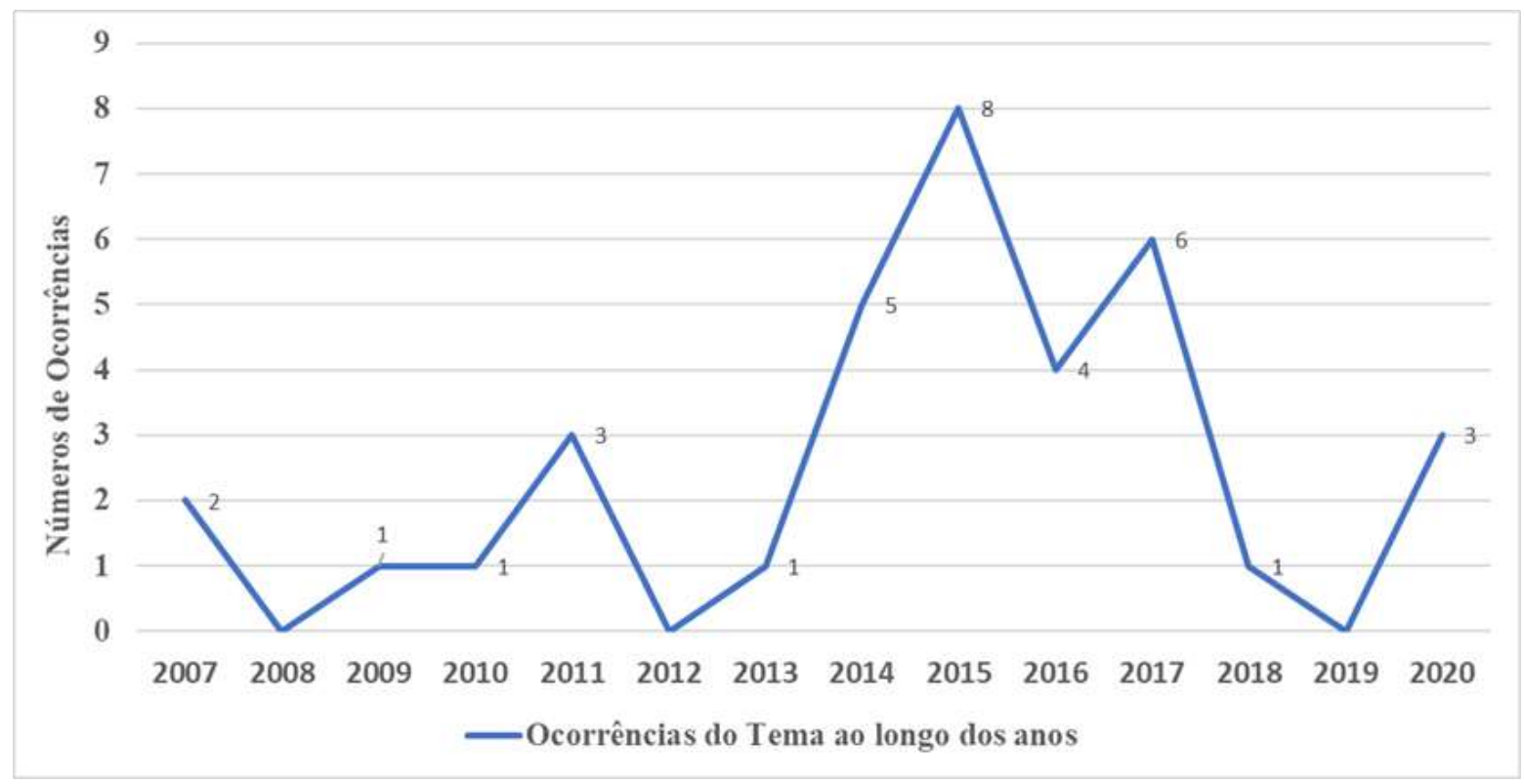

Fonte: Catálogo de base da Capes. 
A base de dados da Capes apontou apenas cinco dissertações associadas a temática adoecimento docente, associadas ao mestrado profissional (Tabela 1). Ressalta-se que apesar de não aparecer explícito no título da dissertação, esse termo foi encontrado pelos pesquisadores no resumo dessas produções. A busca apresentou ainda a ocorrência de três dissertações em 2015, uma publicada em 2017 e outra, mais recentemente em 2020, conforme é possível verificar na tabela abaixo.

Tabela 1. Dissertações de mestrado profissional catalogadas do banco da CAPES.

\begin{tabular}{|c|c|}
\hline \multicolumn{2}{|c|}{ DISSERTAÇÕES DE MESTRADO PROFISSIONAL (5) } \\
\hline $\begin{array}{l}\text { SILVA, JACKELINY DIAS DA. Saúde mental na } \\
\text { escola: uma análise da relação entre cultura } \\
\text { organizacional e estresse' 27/02/2020 } 110 \mathrm{f} \text {. Mestrado } \\
\text { Profissional em Gestão Organizacional Instituição de } \\
\text { Ensino: Universidade Federal de Goiás, Catalão } \\
\text { Biblioteca Depositária: UFG. }\end{array}$ & $\begin{array}{l}\text { OZOLIO, LEANDRO FERNANDO ANDRADE. } \\
\text { Adoecimento funcional docente na rede municipal de } \\
\text { educação de belo horizonte: estudo de caso da regional } \\
\text { Pampulha' 26/08/2015 } 214 \mathrm{f} \text {. Mestrado Profissional em } \\
\text { Gestão e Avaliação da Educação Pública Instituição de } \\
\text { Ensino: Universidade Federal de Juiz de Fora, Juiz de } \\
\text { Fora Biblioteca Depositária: Biblioteca Central da UFJF. }\end{array}$ \\
\hline $\begin{array}{l}\text { LIMA, MARCIA LEAO DE. BIOGRAFEMÁTICA E } \\
\text { ESQUIZOANÁLISE: Procedimentos de escrita de } \\
\text { uma vida docente' 27/02/2015 138 f. Mestrado } \\
\text { Profissional em Educação e Tecnologia Instituição de } \\
\text { Ensino: Instituto Federal de Educ., Ciênc. e Tecn. Sul- } \\
\text { Rio-Grandense, Pelotas Biblioteca Depositária: } \\
\text { Instituto Federal de Educação, Ciência e Tecnologia } \\
\text { Sul-rio-grandense / Câmpus Pelotas. }\end{array}$ & $\begin{array}{l}\text { COROCHER, MAISA DA SILVA. Programa de } \\
\text { acompanhamento psicossocial dos servidores da } \\
\text { educação (papse) da Seduc/am: os desafios acerca do } \\
\text { absenteísmo docente' 21/12/2017 } 117 \text { f. Mestrado } \\
\text { Profissional em Gestão e Avaliação da Educação Pública } \\
\text { Instituição de Ensino: Universidade Federal de Juiz de } \\
\text { Fora, Juiz de Fora Biblioteca Depositária: Biblioteca } \\
\text { Central da UFJF. }\end{array}$ \\
\hline$V: l^{\wedge}$ & $\begin{array}{l}\text { abalho docente' 31/07/2015 } 169 \text { f. Mestrado Profissional } \\
\text { ino: Universidade Federal do Paraná, Curitiba Biblioteca }\end{array}$ \\
\hline
\end{tabular}

Fonte: Bases de Dados da Capes.

Sobre esses dados, Gatti (2014) afirma que os mestrados profissionais devem ter o foco nas dinâmicas relacionais de trabalho nas organizações educacionais e seus consequentes, além disso, devem mobilizar conhecimentos que permitam melhor qualificação do trabalho. Assim, percebe-se que embora Gatti (2014) mostre que a função dos mestrados profissionais seja contribuir para as dinâmicas relacionais dos ambientes de trabalho, esse tipo de pós-graduação não tem produzido uma quantidade considerável de pesquisas sobre a temática “Adoecimento Docente”, tendo em vista que o mestrado profissional é uma modalidade de formação pós-graduada que visa à qualificação profissional, é instigante compreender a baixa produção cientifica relacionada ao tema pelos programas de mestrado profissional no Brasil.

Segundo Cevallos e Passos (2012), esses cursos tornam-se alternativas interessantes, uma vez que as iniciativas de formação continuada comumente oferecidas aos professores dos ensinos fundamental e médio são cursos de curta duração, desarticulados de sua prática e não tem produzido resultados completos. Os cursos de mestrado profissionais buscam atender às demandas da sociedade em meio às novas exigências requeridas do profissional professor que busca seu desenvolvimento na atual conjuntura das políticas voltadas para uma formação docente de qualidade.

Para Ribeiro (2006), o que se almeja é algo aparentemente simples, mas bastante ambicioso e difícil, que o aluno entenda a importância da pesquisa em sua área profissional, que saiba onde encontrar a pesquisa ainda não feita, mas que se fará no futuro e finalmente, que seja capaz de incorporá-la em seu exercício da profissão.

No contexto das dissertações de mestrados acadêmicos, a análise apontou 22 publicações associadas ao tema adoecimento docente por meio da base de dados da CAPES, no período de 2007 a 2020. Deste total, constatou-se destaque do ano de 2017, que obteve 5 dissertações, em seguida 2014 com 4 inserções (Tabela 2). 
Tabela 2. Dissertações do mestrado Acadêmicos catalogadas do banco da CAPES.

\begin{tabular}{|c|c|c|}
\hline \multicolumn{3}{|c|}{ DISSERTAÇÕES DE MESTRADO ACADÊMICO (22) } \\
\hline $\begin{array}{l}\text { GONCALVES, ESTER DUARTE. } \\
\text { Vulnerar Direitos: Construção } e \\
\text { Corrosão da Carreira do Magistério } \\
\text { Paulista' 20/11/2020 } 129 \text { f. Mestrado } \\
\text { em Educação Instituição de Ensino: } \\
\text { Universidade Estadual de Campinas, } \\
\text { Campinas Biblioteca Depositária: } \\
\text { Biblioteca Central. }\end{array}$ & $\begin{array}{lr}\text { MEDEIROS, } & \text { ROSANA } \\
\text { CARNEIRO FERREIRA. Para } \\
\text { uma Ecologia (Mais) Humana Do } \\
\text { Professor Readaptado' 01/03/2010 } \\
217 \text { f. Mestrado em Educação } \\
\text { Instituição de Ensino: } \\
\text { Universidade de Brasília, Brasília } \\
\text { Biblioteca Depositária: BCE UNB. }\end{array}$ & $\begin{array}{l}\text { SOLDATELLI, ROSANGELA. } \\
\text { O Processo de Adoecimentos dos } \\
\text { Professores do Ensino } \\
\text { Fundamental de Florianópolis e } \\
\text { Suas Possibilidades de } \\
\text { Resistência a esse Processo' } \\
01 / 12 / 2011 \text { f. Mestrado em } \\
\text { Educação Instituição de Ensino: } \\
\text { Universidade Federal de Santa } \\
\text { Catarina, Florianópolis Biblioteca } \\
\text { Depositária: Biblioteca } \\
\text { Universitária. }\end{array}$ \\
\hline $\begin{array}{l}\text { BORDALO, KARINA BARBOSA. } \\
\text { Interfaces entre Trabalho } e \\
\text { Adoecimento Docente' 25/11/2014 } 103 \\
\text { f. Mestrado em Educação Instituição de } \\
\text { Ensino: Universidade do Estado do } \\
\text { Pará, Belém Biblioteca Depositária: } \\
\text { Paulo Freire. }\end{array}$ & $\begin{array}{l}\text { Reis, Maria Izabel Alves dos. } \\
\text { Gestão, Trabalho e Adoecimento } \\
\text { Docente: } \\
\text { Desencaminhos na Escola Bosques } \\
\text { 01/03/2009 } 157 \mathrm{f} \text {. Mestrado em } \\
\text { Educação Instituição de Ensino: } \\
\text { Universidade Federal do Pará, } \\
\text { Belém Biblioteca Depositária: } \\
\text { Elcy Rodrigues Lacerda/Instituto } \\
\text { de Ciências da Educação. }\end{array}$ & 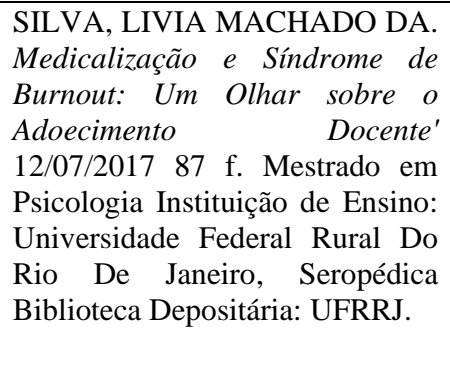 \\
\hline $\begin{array}{l}\text { MARCELINO, ANA LUCIA } \\
\text { GONÇALVES. Adoecimento Docente: } \\
\text { Narrativas do Trabalho em Busca do } \\
\text { Queviver' 01/09/2011 } 73 \text { f. Mestrado em } \\
\text { Educação Instituição de Ensino: } \\
\text { Universidade Federal do Rio Grande do } \\
\text { Sul, Porto Alegre Biblioteca } \\
\text { Depositária: Biblioteca Setorial de } \\
\text { Educação. }\end{array}$ & $\begin{array}{l}\text { REIS, JULIANA CHRISTINA DE } \\
\text { SOUZA. Impactos das Políticas } \\
\text { Públicas Educacionais Mineiras, } \\
\text { no Período de } 2003 \text { a 2014, sobre } \\
\text { a Saúde do Professor da Rede } \\
\text { Estadual de Uberaba' 23/02/2017 } \\
83 \text { f. Mestrado em Educação } \\
\text { Instituição de } \\
\text { Universidade Federal do Triângulo } \\
\text { Mineiro, Uberaba Biblioteca } \\
\text { Depositária: UFTM. }\end{array}$ & 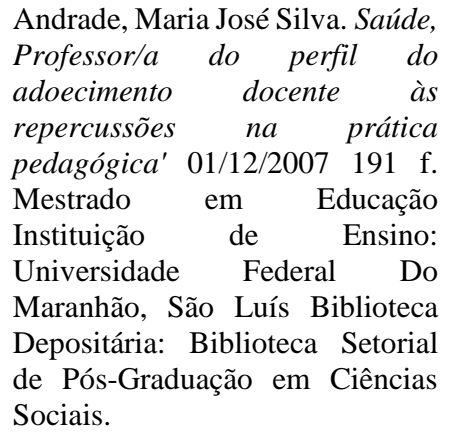 \\
\hline $\begin{array}{l}\text { SOUSA, ADRIANA MODESTO DE. } O \\
\text { Perfil do Adoecimento Docente na } \\
\text { Universidade de Brasília de } 2006 \text { a } \\
2011^{\prime} \text { 28/02/2013 } 102 \mathrm{f} \text {. Mestrado em } \\
\text { Ciências da Saúde Instituição de Ensino: } \\
\text { Universidade de Brasília, Brasília } \\
\text { Biblioteca Depositária: Biblioteca } \\
\text { Central - Bce. }\end{array}$ & $\begin{array}{l}\text { SANTANA, } \\
\text { FRANCIELE } \\
\text { ARIENE LOPES. Trabalho e } \\
\text { Desgaste em Docentes de } \\
\text { Instituições Públicas de Educação } \\
\text { Superior Brasileiras' } 29 / 03 / 2017 \\
125 \text { f. Mestrado em Educação } \\
\text { Instituição de Ensino: Fundação } \\
\text { Universidade Federal de Mato } \\
\text { Grosso do Sul, Corumbá } \\
\text { Biblioteca Depositária: UFMS. }\end{array}$ & $\begin{array}{l}\text { COUTO, ANDREA LOBATO. } \\
\text { Adoecimento de Docentes na } \\
\text { Educação Básica: Uma Revisão } \\
\text { Sistemática da Literatura } \\
31 / 01 / 2018 \text { f. Mestrado em } \\
\text { Educação Instituição de Ensino: } \\
\text { Universidade Federal do Pará, } \\
\text { Belém Biblioteca. }\end{array}$ \\
\hline $\begin{array}{l}\text { BARROS, CLAUDIA MARIA } \\
\text { RODRIGUES. O Trabalho Docente e o } \\
\text { processo de Adoecimento no Curso de } \\
\text { Educação Física Da Universidade do } \\
\text { Estado do Pará' 27/08/2014 } 122 \text { f. } \\
\text { Mestrado em Educação Instituição de } \\
\text { Ensino: Universidade do Estado do } \\
\text { Pará, Belém Biblioteca Depositária: } \\
\text { Paulo Freire. }\end{array}$ & $\begin{array}{l}\text { CABRAL, TALITHA ESTEVAM } \\
\text { MOREIRA. O processo de } \\
\text { adoecimento do magistério público } \\
\text { primário no início do século XX: } \\
\text { indícios do mal estar docente nos } \\
\text { grupos escolares mineiros (1906- } \\
1930)^{\prime} \text { 28/05/2014 } 143 \text { f. Mestrado } \\
\text { em Educação Instituição de } \\
\text { Ensino: Universidade Federal de } \\
\text { Viçosa, Viçosa Biblioteca. }\end{array}$ & $\begin{array}{l}\text { TORRES, JUSCELINA MARIA } \\
\text { DIAS. O ser Professor na Rede } \\
\text { Municipal de Uberlândia: } \\
\text { Histórias Atravessadas Pela } \\
\text { Readaptação Funcional - } 2000 \text { a } \\
\text { 2014' 27/08/2015. Mestrado em } \\
\text { História Instituição de Ensino: } \\
\text { Universidade Federal De } \\
\text { Uberlândia, } \\
\text { Biblioteca. }\end{array}$ \\
\hline
\end{tabular}




\begin{tabular}{|c|c|c|}
\hline $\begin{array}{l}\text { RESENDE, CARLOS EDUARDO DE } \\
\text { ANDRADE. Contribuições da } \\
\text { Psicologia do Trabalho para o } \\
\text { entendimento da saúde mental de } \\
\text { professores de escolas regulares da } \\
\text { rede particular de Belo Horizonte } \\
11 / 07 / 2016 \text { 117 f. Mestrado em } \\
\text { Psicologia Instituição de Ensino: } \\
\text { Pontifícia Universidade Católica de } \\
\text { Minas Gerais, Belo Horizonte } \\
\text { Biblioteca Depositária: Biblioteca Pe. } \\
\text { Alberto Antoniazz. }\end{array}$ & $\begin{array}{l}\text { MENDES, MARIA LUIZA } \\
\text { MACIEL. A Saúde Docente no } \\
\text { Contexto da Política de } \\
\text { Valorização do Magistério: O } \\
\text { Caso Do Municipio Do Recife.' } \\
\text { 01/09/2007 } 108 \text { f. Mestrado em } \\
\text { Educação Instituição de Ensino: } \\
\text { Universidade Federal de } \\
\text { Pernambuco, Recife Biblioteca } \\
\text { Depositária: Biblioteca Central da } \\
\text { UFPE. }\end{array}$ & 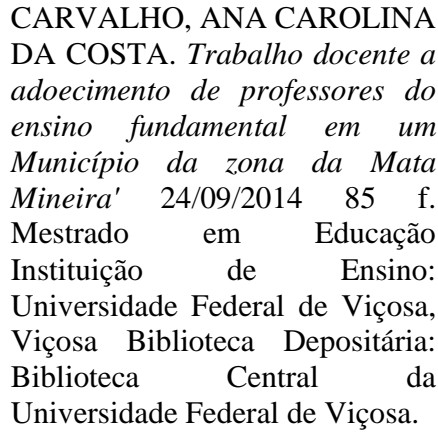 \\
\hline $\begin{array}{l}\text { FREITAS, NATIELLEN QUATRIN. } \\
\text { Adoecimento Relacionado ao Trabalho } \\
\text { de Docentes Universitários da Área da } \\
\text { Saúde' 20/03/2015. Mestrado em } \\
\text { Enfermagem Instituição de Ensino: } \\
\text { Universidade Federal de Santa Maria, } \\
\text { Santa Maria Biblioteca Depositária: } \\
\text { Biblioteca Central da UFSM. }\end{array}$ & $\begin{array}{l}\text { Júnior, William Pessôa da Mota. } \\
\text { Os Impactos do Sistema Capes de } \\
\text { Avaliação sobre o Trabalho } \\
\text { Docente na Pós-Graduação: O } \\
\text { Caso da Ufpa.' 01/04/2011 } 208 \mathrm{f} \text {. } \\
\text { Mestrado em Educação Instituição } \\
\text { de Ensino: Universidade Federal } \\
\text { do Pará, Belém. Biblioteca } \\
\text { Depositária: Biblioteca Prof }{ }^{a} \text { Elcy } \\
\text { Rodrigues Lacerda - ICED - } \\
\text { UFPA. }\end{array}$ & 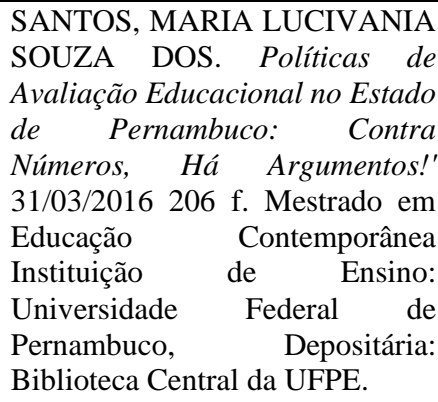 \\
\hline
\end{tabular}

BERNARDINI, PRISCILE. Estudo correlacional sobre autoeficácia e Burnout no trabalho docente no ensino superior' 29/03/2017 103 f. Mestrado em Educação Instituição de Ensino: Universidade do Oeste Paulista, Presidente Prudente Biblioteca Depositária: Rede de Bibliotecas da Unoest.

Fonte: Bases de Dados da Capes.

Também a dissertação de mestrado deve cumprir as exigências da monografia científica. Trata-se da comunicação dos resultados de uma pesquisa, análise e reflexão, que versa sobre um tema igualmente único e delimitado. Deve ser elaborada de acordo com as mesmas diretrizes metodológicas, técnicas e lógicas do trabalho científico, como na tese de doutorado (Severino, 2017).

Em relação as teses de Doutorado acadêmico a análise apontou apenas 8 produções associadas ao tema através da base de dados da CAPES, no período de 2007 a 2020. Com destaque no ano de 2015 que obteve 3 pesquisas, em seguida o ano de 2016 com 2 publicações, conforme é possível constatar na Tabela 3.

Ao consideramos o período de 13 anos como janela temporal de publicação de teses de doutorado, o total de oito publicações é uma quantidade de produções muito escassa e mostra que o tema tem sido pouco abordado pelos níveis mais profundo de ensino. Entretanto, vale ressaltar que uma dissertação ou tese de mestrado pode gerar no mínimo 2 a 3 artigos acadêmicos.

A tese de doutorado é considerada o tipo mais representativo do trabalho científico. Trata-se da abordagem de um único tema, que exige pesquisa própria da área científica em que se situa, com os instrumentos metodológicos específicos. Essa pesquisa pode ser teórica, de campo, documental, experimental, histórica ou filosófica, mas sempre versando sobre um tema único, específico, delimitado e restrito (Severino, 2017).

A diferença fundamental em relação à tese de doutorado está no caráter de originalidade do trabalho. Tratando-se de um trabalho ainda vinculado a uma fase de iniciação à ciência, de um exercício diretamente orientado, primeira manifestação de um trabalho pessoal de pesquisa, não se pode exigir da dissertação de mestrado o mesmo nível de originalidade e o mesmo alcance de contribuição ao progresso e desenvolvimento da ciência em questão (MATCZAK, 1971, p. 17). 
Tabela 3. Teses acadêmicos catalogadas do banco da Capes.

\begin{tabular}{|c|c|}
\hline \multicolumn{2}{|c|}{ TESES DE DOUTORADO (8) } \\
\hline $\begin{array}{l}\text { DIAS, CRISTINA DAMM } \\
\text { estranhamento como nexo causal do adoecimento } \\
\text { docente na Universidade Federal de Uberlândia' } \\
\text { 14/12/2017 } 172 \text { f. Doutorado em EDUCAÇÃO } \\
\text { Instituição de Ensino: UNIVERSIDADE FEDERAL DE } \\
\text { UBERLÂNDIA, Uberlândia Biblioteca Depositária: }\end{array}$ & $\begin{array}{l}\text { JUNIOR, RAIMUNDO SERGIO DE FARIAS. A } \\
\text { Precarização do Trabalho e o Adoecimento } \\
\text { Docente em Instituições de Ensino Superior } \\
\text { Privadas/Mercantis' } 18 / 06 / 2014269 \mathrm{f} \text {. Doutorado } \\
\text { em EDUCAÇÃO Instituição de Ensino: } \\
\text { UNIVERSIDADE FEDERAL DO PARÁ, Belém } \\
\text { Biblioteca Depositária: Elcy Rodrigues Lacerda. }\end{array}$ \\
\hline $\begin{array}{l}\text { MENDES, MARIA LUIZA MACIEL. Tradução do } \\
\text { Fracasso: Burnout em Professores do Recife } \\
\text { 24/07/2015 } 139 \text { f. Doutorado em Educação Instituição } \\
\text { de Ensino: Universidade Federal de Pernambuco, Recife } \\
\text { Biblioteca Depositária: Biblioteca Central da UFP. }\end{array}$ & $\begin{array}{l}\text { FERNANDES, LUCIETE VALOTA. O processo } \\
\text { grupal como resistência ao sofrimento e ao } \\
\text { adoecimento docente: um estudo à luz da } \\
\text { perspectiva histórico-dialética' 30/09/2015 } 270 \mathrm{f} \text {. } \\
\text { Doutorado em Psicologia Escolar e do } \\
\text { Desenvolvimento Humano Instituição de Ensino: } \\
\text { Universidade de São Paulo, São Paulo Biblioteca } \\
\begin{array}{l}\text { Depositária: Biblioteca Dante Moreira Leite, } \\
\text { Instituto de Psicologia. }\end{array}\end{array}$ \\
\hline $\begin{array}{l}\text { DIAS, MARIA JOSE PEREIRA DE OLIVEIRA. Mal- } \\
\text { Estar e Adoecimento Docente no Contexto da Educação } \\
\text { Infantil.' 18/06/2020 } 189 \text { f. Doutorado em Educação } \\
\text { Instituição de Ensino: Pontifícia Universidade Católica } \\
\text { de Goiás, Goiânia Biblioteca Depositária: PUC Goiás. }\end{array}$ & $\begin{array}{l}\text { GOUVEA, LEDA APARECIDA VANELLI } \\
\text { NABUCO DE. Saúde como Direito Social na pauta } \\
\text { Sindical de Professores da Rede Básica de Ensino' } \\
\text { 14/09/2015 } 344 \text { f. Doutorado em Políticas Públicas } \\
\text { e Formação Humana Instituição de Ensino: } \\
\text { Universidade do Estado do Rio de Janeiro, Rio de } \\
\text { Janeiro Biblioteca. }\end{array}$ \\
\hline $\begin{array}{l}\text { JUNIOR, PAULO ROBERTO VIEIRA. SAÚDE } \\
\text { DOCENTE E CONDIÇÕES DE TRABALHO: estudo } \\
\text { quantiqualitativo realizado em uma instituição da Rede } \\
\text { Federal de Educação Profissional Científica e } \\
\text { Tecnológica de Minas Gerais' 01/06/2016 } 268 \text { f. } \\
\text { Doutorado em Educação Instituição de Ensino: } \\
\text { Pontifícia Universidade Católica de Minas Gerais, Belo } \\
\text { Horizonte Biblioteca Depositária: PUC Minas. }\end{array}$ & $\begin{array}{l}\text { OLIVEIRA, MARIANA ESTEVES DE. } \\
\text { "Professor, você Trabalha ou só dá Aula?" -O } \\
\text { Fazer-Se Docente Entre História, Trabalho e } \\
\text { Precarização na SEE-SP' 20/04/2016 266 f. } \\
\text { Doutorado em História Instituição de Ensino: } \\
\text { Universidade Federal da Grande Dourados, } \\
\text { Dourados Biblioteca Depositária: UFGD. }\end{array}$ \\
\hline
\end{tabular}

Fonte: Bases de Dados da Capes.

A pós-graduação no Brasil foi regulamentada pelo Parecer nº 977/65 do Conselho de Educação Superior (CESU). Além de definir as características e conceitos dos cursos de mestrado e doutorado, e estruturar a pós-graduação brasileira nos moldes do sistema norte-americano, este parecer trata da distinção entre a pós-graduação Stricto Sensu e lato sensu. O parecer define a pós-graduação lato sensu como todo e qualquer curso que se segue à graduação, tais como os de especialização e aperfeiçoamento, ou seja, os que são mais direcionados à atualização dos alunos graduados. Os cursos Stricto Sensu são aqueles com objetivos mais amplos e aprofundados de formação científica e profissional, que se sobrepõem à graduação, sendo parte integrante do complexo universitário (Brasil, 1965).

\section{Considerações Finais}

O mapeamento referente à pesquisa realizada no Banco de Teses da Coordenação de Aperfeiçoamento de Pessoal de Nível Superior - CAPES, permitiu investigar a presença da temática de “Adoecimento Docente”, nas produções científicas em programas de pós-graduação Stricto Sensu em nível de mestrado e doutorado de universidades brasileiras, no período de 2007 a 2020 .

A análise de conteúdo das teses e dissertações investigadas nesta pesquisa corroborou a percepção de que existe uma carência no cenário nacional de trabalhos que tratem especificamente do adoecimento docente. Destaca-se que dos três tipos de pós-graduação Strito Sensu, o mestrado acadêmico apresentou um número maior de produção cientificas e a menor quantidade de pesquisas sobre o tema foram produzidas pelo mestrado profissional. 
Este mapeamento evidenciou a necessidade de aprofundar-se na continuidade desta pesquisa para poder ampliar o estudo referente aos dados de análise sobre esta temática. Porém, fica demonstrado pelos números expressos nos resultados desta pesquisa que há um declínio nas produções referentes à temática proponente, corroborando para a relevância de se fomentarem futuras pesquisas que incluam essa temática, pois os números ainda são incipientes. Diante dos resultados, sugere-se a ampliação de estudos que apresentem propostas direcionadas para a saúde mental desses profissionais ao longo da pandemia considerando que houve aumento da sobrecarga de trabalho, novos desafios e ausência da disponibilização de suporte emocional docente durante a pandemia. Ressaltamos que nessa análise não foram contabilizados os artigos que são derivados das dissertações e teses que colaboram para ampliação desta temática.

\section{Referências}

Abonízio, G. (2012). Precarização do trabalho docente: apontamentos a partir de uma análise bibliográfica. Revista Eletrônica Lenpes - PIBID de Ciências Sociais- Edição, 1(1).

Assunção, A. A (2003). Saúde e Condições de Trabalho nas Escolas Públicas. IN: Oliveira, D.A. (Org.) Reformas Educacionais na América Latina e os Trabalhadores Docentes. Autêntica, 87-102.

Bardin, L. (2016). Análise de conteúdo. Edições 70.

Benevides-Pereira, A. M. T. (2012). Considerações sobre a síndrome de burnout e seu impacto no ensino. Boletim de Psicologia, 62(137), 155-168.

Brasil. CESu/CFE. (2016). Parecer 977 de 03 de dezembro de 1965 (1965). Dispõe sobre a definição da natureza e objetivos dos cursos de pós-graduação no Brasil.

Cardoso, J. S., Nunes, C. P., \& Moura, J. S. (2019). Adoecimento docente: Uma breve análise da saúde de professores do Município de Medeiros Neto/BA. Revista Teias v. 20(57).

Cevallos, I., \& Passos, L. F. (2012). O mestrado profissional e a pesquisa do professor. Revista Diálogo Educacional, 12(37), 803-822.

Ferreira, J. L., \& Matos, Elizete Lúcia Moreira. (2012). Mapeando o conhecimento científico em teses e dissertações na pedagogia hospitalar. In: $1^{\text {o }}$ Seminário de Educação Popular e Saúde e $7^{\circ}$ Encontro Nacional de Atendimento Hospitalar, Natal. Anais. Natal, p. 1-10.

Gonzalez, T. (2020). Influência do confinamento Covid-19 no desempenho dos alunos no ensino superior. ArXiv.org.

Ferreira, N. S. A. (2002). As pesquisas denominadas "estado da arte". Educação \& Sociedade, 2 (79).

Gatti, B. A. (2014). A Pesquisa em Mestrados Profissionais. In: Fompe - Fórum de Mestrados Profissionais em Educação, I., Salvador. Trabalhos apresentados. Salvador: UNEB.

Lago, R. R., Cunha, B. S., \& Borges, M. F. de S. O (2015). Percepção do trabalho docente em uma universidade da Região Norte do Brasil. Trabalho, Educação e Saúde, 13(2), 429-450. 10.1590/1981-7746-sip00049.

Lemos, D. (2011). Trabalho docente nas universidades federais: tensões e contradições. Caderno CRH, 24 (01), $105-120$.

Lima, M. D. F. E. M., \& Lima-Filho, D. D. O. (2009). Condições de trabalho e saúde do/a professor/a universitário/a. Ciências \& Cognição, 14(3), 62-82. R http://pepsic.bvsalud.org/ scielo.php?pid=S180658212009000300006\& script=sci_arttext

Lopes, M. I. V., \& Romancini, R. (2006). Teses e dissertações: estudo bibliométrico na área da comunicação. In D. A. Poblacion, G. P. Witter, \& J. F. M. da Silva (Orgs.), Comunicação \& produção cientifica: contexto, indicadores e avaliação. Angellara. 235-259.

Marques, R. (2021). O professor em trabalho remoto no contexto da pandemia da covid-19. Boletim De Conjuntura (BOCA),6(16), 06-14. https://doi.org/10.5281/zenodo.4642898.

Mancebo, D., Ewald, A., Prestrelo, E. T., \& Uziel, A. P. (2006). Em discussão: o trabalho docente. Editorial. Revista Estudos e Pesquisas em Psicologia. 6(6).

Matczak, S. A. (1971). Research and composition in philosophy. (2a ed.), Béatrice/Neuwelaerts, p 88.

Mendes, A. M., \& Ferreira, M. C. (2007). Inventário sobre Trabalho e Risco de Adoecimento - ITRA: Instrumento auxiliar de diagnóstico de indicadores críticos no trabalho. In A. M. Mendes (Ed.). Psicodinâmica do Trabalho: teoria, método e pesquisas. Casa do Psicólogo, p. 111-126.

Oliveira, E.C., \& Santos, V.M. (2021). Adoecimento mental docente em tempos de pandemia. Brazilian Journal of Development, 7(4), 39193-39199.

Pachiega, M. D., \& Milani, D. R. C. (2020). Pandemia, as reinvenções educacionais e o mal-estar docente: uma contribuição sob a ótica psicanalítica. Dialogia, $36,220-234$.

Piton, N. N., \& Machado, C. (2019). Clima escolar: mapeamento e análise de artigos científicos constantes no portal de periódicos CAPES. Revista @ mbienteeducação. Universidade Cidade de São Paulo, 12(1), 50-67. 
Research, Society and Development, v. 10, n. 10, e373101018718, 2021

(CC BY 4.0) | ISSN 2525-3409 | DOI: http://dx.doi.org/10.33448/rsd-v10i10.18718

Ribeiro, R. J. (2006). Ainda sobre o mestrado profissional. RBPG, 2(6), 313-315.

Romanowski, J. P., \& Ens, R. T. (2006). As pesquisas denominadas do tipo "estado da arte" em educação. Revista Diálogo Educacional, PUCPR, 6, $37-50$.

Sampaio, M. das M. F., \& Marin, Alda J. (2004). Precarização do trabalho docente e seus efeitos sobre as práticas curriculares. Educ. Soc. Campinas, 25(89), $1203-1225$.

Santos, Vanice dos \& Candeloro, Rosana. (2006). Trabalhos acadêmicos: uma orientação para a pesquisa e normas técnicas. AGE Ltda.

Severino, A. J. (2017). Metodologia do trabalho científico. (2a ed.), Cortez.

Silva, A. F., Estrela, F. M., Lima, N. S., \& Abreu, C. T. de A. (2020). Saúde mental de docentes universitários em tempos de pandemia. Physis: Revista de Saúde Coletiva, Rio de Janeiro, v. 30(2), e300216, 1-4.

Tundis, A. G. O., \& Monteiro, J. K. (2018). Ensino Superior e Adoecimento Docente: Um Estudo Em Uma Universidade Pública. Psic. da Ed., 46, 1-10.

Vasconcelos, I., \& Lima, R. D. L. (2021). Trabalho e saúde-adoecimento de docentes em universidades públicas. Revista Katál, 24(2), 364-374. 